\title{
Comunicação, educação e cidadania: diálogos possíveis ${ }^{1}$
}

\section{Communication, education and citizenship: possible dialogues}

\author{
Luciana Barbosa de Feitas ${ }^{2}$ \\ (lubfreitasgoias@yahoo.com.br) \\ Simone Antoniaci Tuzzo ${ }^{3}$ \\ (simonetuzzo@hotmail.com) \\ http://dx.doi.org/10.5216/cei.v16i1.26654
}

\begin{abstract}
Resumo
A comunicação é diálogo, e é sem dúvida algo inerente à vida humana. Pretende-se aqui esboçar uma análise sobre como a educação e a comunicação, como fenômenos humanos, contribuem com a construção da cidadania na sociedade midiática, cheia de tecnologias. Ao longo do estudo faz-se uma leitura acerca da comunicação na centralidade da sociedade midiática percebendo o quanto essa sociedade contribui para a formação de uma nova aprendizagem e, finalmente, discorre-se a respeito do diálogo entre os saberes Comunicação e Educação. Espera-se que esta análise possa constituir elementos norteadores para novos olhares e apontar caminhos para os campos ora estudados.
\end{abstract}

Palavras-chave: Educação. Mídia. Tecnologias. Cidadania.

\begin{abstract}
The communication is dialogue, and is definitely something inherent in human life. The intention here is to outline an analysis of how education and communication as human phenomena contribute to the construction of citizenship in the media society, full of technology. Throughout the study it is a reading about the centrality of communication in media society realizing how this society contributes to the formation of a new learning and finally talks to about the dialogue between the knowledge Communication and Education. It is hoped that this analysis can provide new insights for guiding elements and point the way to the fields studied herein.
\end{abstract}

Keywords: Education. Media. Technology. Citizenship.

\section{Introdução}

s características da sociedade atual são marcadas, principalmente, pela inovação,
criatividade, tecnologia, mídia, Internet, redes sociais, mídias digitais, celulares, enfim, pelas tecnologias midiáticas. Cada vez mais a comunicação acontece por meio dos celulares, das redes sociais, e-mails, chats, teleconferências, vídeos-conferências e

\footnotetext{
${ }^{1}$ Mestranda em Comunicação, pela FACOMB/UFG, Psicopedagoga pela PUC/GO, Especialista em Métodos e Técnicas de Ensino, pela UNIVERSO/GO e Graduada em Pedagogia, pela FE/UFG. Atualmente coordena a área de Desenvolvimento Institucional do CDI em Goiás.

${ }^{2}$ Pós-Doutoranda e Doutora em Comunicação e Cultura pela Universidade Federal do Rio de Janeiro (2003); Mestrado em Comunicação Social pela Universidade Metodista de São Paulo (1997); Graduada em Relações Públicas pela Universidade Metodista de São Paulo (1988). É Professora Efetiva do Programa de Mestrado em Comunicação e Professora Adjunta II da Faculdade de Comunicação e Biblioteconomia da UFG - Universidade Federal de Goiás, lecionando no Curso de Relações Públicas. Coordenadora do Curso de Especialização em Assessoria de Comunicação e Marketing da UFG.
} 
webconferências, etc. Isso tem ampliado a possibilidade de acesso à informação e, também, possibilita outras situações.

Para Levy (1999, p. 32), as tecnologias digitais "surgiram, então, como a infraestrutura do ciberespaço, novo espaço de comunicação, de sociabilidade, de organização e de transação, mas também novo mercado da informação e do conhecimento". É notório o quanto as mídias têm ampliado a possibilidade de interação social entre as mais diversas culturas e sociedades.

As mudanças socioeconômicas, culturais e políticas que ocorreram nas últimas décadas e a necessidade da América Latina ser fortalecida ao contexto do novo mundo ampliam, cada vez mais, a necessidade de discutir a questão da cidadania. A sociedade tem se tornado multidimensional, isso tem requerido uma educação para cidadania e requer, também, uma educação para um mundo intermediado pela mídia.

Os dispositivos eletrônicos e tecnológicos evoluem, desenvolvem e se popularizam. Contudo, fazer uso com criatividade e competência dos conteúdos midiáticos não são tarefas fáceis para os chamados 'nativos digitais' (PRENSKY, 2001), muito mais acostumados com a ferramenta do que a lógica de interpretação. Dowbor (2001) explica que:

As tecnologias em si não são ruins. Fazer mais coisas com menos esforço é positivo. Mas as tecnologias sem a educação, conhecimentos e sabedoria que permitam organizar o seu real aproveitamento, levam-nos apenas a fazer mais rápido e em maior escala os mesmos erros (DOWBOR, 2001, p. 4).

Portanto, as preocupações que orientam o presente texto se agrupam na seguinte reflexão: é possível, numa sociedade midiática, cheia de tecnologia, que a educação e a comunicação como fenômenos humanos contribuam com a construção da cidadania?

Nessa perspectiva, quais contribuições a Comunicação (com maior ênfase para as mídias) e a Educação (no que tange à formação humana) trazem para a efetivação da cidadania plena na Era atual? Assim, por meio de uma análise bibliográfica, estabeleceu-se uma investigação em busca de compreender a relação da Educação e da Comunicação trazendo fundamentos para perceber se há diálogo entre estes saberes.

\section{A comunicação na centralidade da sociedade midiática}

É sabido que o campo teórico da Comunicação traz consigo contribuições das mais variadas ciências já consolidadas, que foram e continuam sendo importantes para seu desenvolvimento, 
como a Filosofia, a Psicologia, a Linguística, dentre outras. Nesse sentido, é possível compreender porque falar em Teorias e não em Teoria da Comunicação.

O direito à comunicação nesta Sociedade Midiática refere-se, não apenas, ao direito às informações, disponíveis tão facilmente nas redes virtuais, por exemplo, mas ao acesso aos bens multiculturais da humanidade (como as artes, a cultura, o conhecimento) e também, aos direitos civis, políticos, econômicos, sociais e os culturais.

Assim, torna-se fundamental ao sujeito saber se comunicar, não bastando apenas reter e transmitir informações. Comunicar é muito mais do que isso. É essencial que saiba interpretar e selecionar, relacionar e analisar (VOSGERAU, 2012). Deste modo o sujeito não corre o risco de ficar alheio ao que acontece ao seu redor.

As autoras Nery e Temer (2009) defendem que comunicação é a "capacidade humana cuja aquisição remonta às origens do desenvolvimento humano e da própria sociedade". Esta capacidade está ligada à habilidade que o homem desenvolve constantemente ao se relacionar com o outro. $\mathrm{O}$ ser humano ao longo dos tempos tem desenvolvido técnicas e tecnologias "que ampliam seu poder e dimensão, transformando profundamente sua forma de relacionamento com sua cultura e estrutura social” (NERY; TEMER, 2009, p. 10).

Um dos campos teóricos da Comunicação que tem contribuído com essa discussão é o Paradigma Midiológico Tecnológico. “Trata-se de modelo histórico-técnico-evolucionista que entende que o desenvolvimento humano é consequência ou está diretamente ligado ao domínio das ferramentas e a seu desenvolvimento tecnológico" (NERY; TEMER, 2009, p. 113).

Fazem parte deste campo teórico estudiosos da Escola Canadense, que aprofundaram seus estudos nesta discussão, trouxeram pesquisas e várias inferências entendendo que o processo de evolução tecnológico contribui com o desenvolvimento social e cultural, sendo, portanto, seu 'motor', sua principal força.

Várias correntes teóricas foram desenvolvidas a partir desta Escola. Uma delas parte do princípio de que as mudanças têm a ver com a interação do meio, seja tecnológico ou não. Como é o caso de McLuhan, educador canadense, precursor dos estudos 'midiológicos', um dos mais expressivos teóricos desta corrente, foi concludente ao afirmar que 'o meio é a mensagem'.

Marshall McLuhan é universalmente conhecido por seus célebres aforismos, como, por exemplo, The Medium is the Message [O meio é a mensagem] e The Global Village [A aldeia global]. Alguns o desprezam, chamando-o de publicista e determinista. Outros [...] o veneram como um visionário, que teria previsto o desenvolvimento e o impacto da televisão, do computador e da Internet. Todos devem reconhecer que ele foi um dos 
primeiros a chamar a atenção para a importância das mídias na vida individual e coletiva (TREMBLAY, 2011, p. 187).

De acordo com as ideias de McLuhan (1998), os próprios meios são a causa e o motivo das estruturas sociais. Portanto, só pelo fato de existir a tecnologia a vida das pessoas é afetada, mesmo que nem todas as pessoas tenham acesso a ela. Para ele, meio é tudo que altera a relação do sujeito com o ambiente (a sua vida é alterada).

Assim, qualquer mudança na comunicação, a partir da tecnologia ou por qualquer meio, provoca mudanças, em escala, nas relações humanas. Muda o modo de se relacionar com o tempo e com o espaço. Isso não implica dizer que a vida se torna mais fácil ou mais difícil, ela se torna diferente, ela muda.

Em sua obra Os Meios de Comunicação como Extensão do Homem, McLuhan (1998) analisou a forma como os meios de comunicação interferem nos sentidos do ser humano. Como ponto de partida, McLuhan (1998) iniciou pela transmissão oral, antes à Renascença; passando pela visão, a partir do invento da imprensa; chegando ao audiovisual, na era da eletrônica. É notório que essas intervenções possibilitaram cada uma em seu tempo, um fato social que, por sua vez, isolou e/ou aproximou o homem de seu habitat.

Percebe-se que o homem em suas relações sociais está sempre em comunicação. De acordo com Freire, "o mundo humano é, desta forma, um mundo de comunicação" (FREIRE, 1996, p.44). E com a evolução dos meios tecnológicos, a comunicação midiática tem grande importância neste 'mundo de comunicação'.

Entretanto, o processo comunicacional não pode ser entendido apenas por meio do uso das tecnologias da informação, como meio midiático. Este processo deve ser principalmente, humanizado. Para isso, é necessário que o ser humano esteja no centro do processo, valorizando, sobretudo, a comunicação interpessoal.

A esse respeito Nery e Temer (2009, p.114) salientam que nos estudos da Comunicação, a Escola Canadense "entende que as sociedades humanas são moldadas pelos meios através dos quais se comunicam e faz uma releitura da historia da humanidade a partir dos impactos produzidos pela tecnologia na percepção do mundo [...]". Ainda de acordo com as autoras, os estudos da Escola Canadense apontam a importância da Comunicação na formação do indivíduo e da sociedade.

De modo mais forte a Escola Canadense estuda sobre a questão da evolução tecnológica, uma vez que todo este aparato tecnológico e suas constantes transformações contribuem para a quebra de referenciais e muda a forma de o indivíduo perceber o mundo e relacionar-se com os 
outros. Por isso mesmo não dá para ignorar a importância da tecnologia. Porém, estas mudanças devem ser analisadas criticamente.

Ademais, é possível encontrar outras abordagens interessantes para o bojo desta discussão, como é o caso dos estudos do Paradigma Conflitual Dialético. Os estudos mostram que as ideias deste Paradigma se fundam sobre o princípio da contradição, o conflito parece ser parte inerente à vida social (NERY; TEMER, 2009).

As autoras Nery e Temer (2009) explicam que as bases teóricas deste Paradigma "partem do princípio de que os donos dos meios de produção também mantêm o controle (de forma direta ou indireta) dos meios de produção e difusão de informações, ou seja, o controle da mídia”. Afirmam, ainda, que "a classe que controla a produção de bens de consumo usa a mídia para veicular e tornar dominante a sua representação da realidade e sua ideologia, impondo a dominação ideológica e o imperialismo cultural" (NERY; TEMER, 2009, p. 163).

Faz parte deste campo teórico, por exemplo, a Escola Latino-Americana que contribui com reflexões para as discussões acerca dos processos comunicacionais. Para Melo (1998), que defende a construção de uma linha teórica latino-americana, é importante analisar, estudar e interpretar os processos comunicacionais. De acordo com o autor, a Escola Latino-Americana não propõe um modelo ou receitas a serem seguidas. Ele apresenta um dos destaques desta Escola que garante que:

[...] a configuração do pensamento latino-americano sobre a comunicação social resultou de um processo de convergência através do qual pesquisadores nucleados em diferentes instituições nacionais ou internacionais sedimentaram um modo de pensar e interpretar os fenômenos da interação simbólica dentro do continente, confrontando-os com as evidências existentes em outras regiões do planeta" (MELO, 1998, p. 15).

A proposição da Escola Latino-Americana, de acordo com os estudos de Nery \& Temer (2009, p. 170), "é gerar condições para repensar as práticas da comunicação e o papel que os meios massivos podem e devem desempenhar na formação da consciência política dos cidadãos".

A esse respeito, Melo (1999) explica como surgiram as primeiras pesquisas desta corrente:

As primeiras pesquisas de comunicação na América Latina surgem em ambientes tipicamente profissionais. São demandadas pelas emergentes indústrias culturais e constituem fatores decisivos para a formação das primeiras agências privadas dedicadas a estudos de opinião pública, audiência dos mass media ou persuasão dos consumidores. Mas também são estimuladas pelas polêmicas que surgem nas associações jornalísticas, encorajando alguns publicistas eruditos a explorar os documentos disponíveis sobre a memória do campo, em sua dimensão sócio-política (MELO, 1999, p. 01).

É possível imaginar o quanto os meios de comunicação têm o poder de construir a realidade a partir de um recorte no cenário dos fatos e acontecimentos da sociedade. A leitura de mundo e a 
leitura da palavra são fundamentais neste processo. Paulo Freire defendia que o objetivo da Escola é o de ensinar o educando a "ler o mundo" para poder transformá-lo (FREIRE, 1991). É possível, entendendo o mundo a partir de uma leitura crítica, que os recursos midiáticos possam contribuir para despertar o sentimento de pertencimento de todos (enquanto cidadão) neste novo mundo que vem sendo desenhado.

Seguindo a abordagem dos Estudos do Pensamento Latino-Americano é possível, também, entender que a Comunicação e o processo social da informação (ao se transformar em conhecimento) são necessários ao indivíduo na busca e exercício pleno da cidadania. De acordo com a pesquisadora Gobbi (2011), foi a partir da década de 1960 que o Pensamento LatinoAmericano, no campo da Comunicação, ganhou definições e correntes teóricas próprias.

Como afirma os professores Luiz Ramiro Beltrán e José Marques de Melo [...] as pesquisas em nossa área começaram a tomar força na região na segunda metade de 1920. Mas foi precisamente nos anos de 1960, que elas adquiriram uma fisionomia, com definições e correntes teóricas que marcaram, posteriormente, o início da Escola Latino-Americana de Comunicação, embora ainda calcada nas ideias da Escola de Frankfurt e no pensamento marxista (GOBBI, 2011, p. 222/223).

Gobbi (2011) aponta os principais intelectuais que contribuíram e contribuem sobremaneira, a partir da década de 1970, com os Estudos do Pensamento Latino-Americano:

Paulo Freire, Fernando Reyes Matta, Luis Ramiro Beltrán, José Marques de Melo [...] Antonio Pasquali, entre outros, fazem emergir estudos norteadores pela pesquisa-denúncia que apontaram a dependência da comunicação em nosso continente, além de evidenciar o poderio comercial e político dos Estados Unidos (GOBBI, 2011, p. 223).

Ainda de acordo com os estudos da pesquisadora Gobbi (2011), liderados pelas ideias dos autores citados acima, outros estudiosos vêm contribuindo com o Pensamento Latino Americano:

[...] surge um contingente de pesquisadores dos diversos países que compõe nossa região, tais como Guilhermo Ozosco, Margarida Maria Krohling Kunsch, [...] Jesús MartínBarbero, Maria Immacolata Vassalo de Lopes [...] entre outros (GOBBI, 2011, p. 223).

As autoras Nery e Temer (2009, p. 168) destacam que este Pensamento "aponta para a construção de um novo modelo de análise que se preocupa com a mediação social e teórica da comunicação com a cultura popular e com a vida cotidiana”. Nos países da América Latina a compreensão da cidadania e luta democrática tem tons diferentes de outros países. Afinal, estamos falando de uma região sociocultural marcada pela diversidade e pela colonização, onde em cada País existe uma identidade peculiar e única enquanto organização de modernas sociedades. 
Então, os atos comunicativos e o exercício da cidadania plena teriam claramente processos distintos, entre si, e de maneira mais global também não seria diferente. Portanto, as tecnologias de informação não levam em conta as fronteiras físicas entre as nações colocando os indivíduos em uma cultura mundializada e midiatizada.

É interessante ressaltar que a interação social fortalecida pela mídia não é o único caminho ou meio para a construção e exercício da cidadania. A mídia aparece como sendo um destes caminhos e tem contribuição importante, mas, não é o único, singular e excepcional. A esse respeito, Thompson (1998) propõe uma atitude reflexiva e uma abordagem crítica a respeito da natureza e do papel da mídia nas sociedades modernas.

Neste sentido, o autor defende que "há muitas outras formas de interação social, como as existentes entre pais e filhos, entre professores e alunos, entre pares, que continuaram a desempenhar um papel fundamental na formação pessoal e social” (THOMPSON, 1998, p. 46). Ainda a par deste assunto, Thompson (1998, p. 46) distingue três formas de interação:

a) A mais tradicional - a interação face a face;

b) A mediada - através de algum meio de comunicação, como o telefone, por exemplo, $\mathrm{e}$;

c) A quase mediada - o indivíduo recebe a informação através de meios massivos (como os livros, por exemplo), não há como interagir.

Thompson (1998) explica que:

Todas as formas de comunicação implicam um certo grau de distanciamento espaço temporal, certo grau de deslocamento no tempo e no espaço. Mas a extensão deste deslocamento varia grandemente, dependendo das circunstâncias de comunicação e de tipo de meio técnico empregado (THOMPSON, 1998, p. 28).

Desse modo, o autor enfatiza "a importância de pensar nos meios de comunicação em relação aos contextos sociais práticos nos quais os indivíduos produzem e recebem as formas simbólicas mediadas" (THOMPSON, 1998, p. 41). Para o autor, a mídia "tem produzido material importante e interessante", mas o autor alerta que há deficiências que não podem ser negligenciadas.

O autor exemplifica que, "se quisermos entender a natureza da recepção, deveremos nos aproximar dela com uma sensibilidade para os aspectos rotineiros e práticos da atividade receptiva" (THOMPSON, 1998, p. 41). Afinal, cada receptor recebe de modo singular uma mensagem e para cada mensagem recebida há uma interpretação diferente. 
Ele defende "que a recepção dos produtos da mídia é uma rotina, uma atividade prática que muitos indivíduos já integram como parte de suas vidas cotidianas”. Portanto, se torna necessário, cada vez mais, ignorar o fato de que os receptores são meros consumidores passivos dos produtos da mídia. Ainda de acordo com o autor, os estudos "mostraram mais uma vez que a recepção dos produtos da mídia é um processo mais ativo e criativo do que o mito do assistente passivo sugere" (THOMPSON, 1998, p. 42).

Verifica-se, portanto, que o processo de recepção deixa de ser simplesmente aquela ideia inicial de receber uma simples mensagem. Compreende-se que o processo de recepção é bem mais que isso, pois existe uma complexidade neste que o torna peculiar para cada indivíduo. Notadamente é inegável o quanto a Comunicação, neste contexto de Sociedade Midiática, tem se firmado cada vez mais como um espaço de força, de poder e de sociabilidade e, também, se tornado um verdadeiro espaço de interação humana.

Enfim, percebe-se que a Comunicação pode se tornar, sem dúvida, um elemento poderoso de participação e quanto mais pessoas se apropriarem dos processos de produção e circulação de conhecimento, mais terão condições de ampliarem sua autonomia.

\section{Da informação ao conhecimento, uma nova cultura da aprendizagem}

Um novo conceito de sociedade e uma nova cultura da aprendizagem surgem na medida em que a informação oportuniza a construção de conhecimento numa sociedade hipermidiática, dominada cada vez mais pelos sistemas midiáticos; pelos satélites; pela grande rede mundial de computadores.

O que se percebe é que, em muitos casos, tão logo uma criança nasce ela já tem acesso às mídias. E assim, ela vai crescendo, aprendendo a conviver em sociedade e o mundo midiático vai fazendo parte de sua formação, antes mesmo de chegar à escola. A esse respeito, Setton (2010) corrobora com a ideia de que não se aprende mais apenas a partir dos pais e do professor.

[...] é importante enfatizar que as informações e os conhecimentos não são adquiridos unicamente nas relações face a face, com seus pais e professores, como era feito há mais ou menos sessenta anos. Esses novos conhecimentos são adquiridos de maneira não presencial, são adquiridos virtualmente a partir do uso frequente das novas tecnologias (SETTON, 2010, p. 23). 
Já na fase adulta, o sujeito não consegue mais se ver ou se imaginar em outra situação que não a de viver numa sociedade midiática. Nas empresas, no comércio, nas profissões em geral, praticamente tudo envolve tecnologias. E se esse sujeito não está preparado ele fica à margem, pois se cria um novo comportamento humano, uma nova forma de aprendizagem. Muito diferente de quando não se tinha toda essa tecnologia disponível atualmente.

O século XXI é caracterizado por mudanças contínuas, conectividade e acesso aos mais variados recursos do conhecimento. A aprendizagem encontrou novos caminhos para o processo do aprender. Já não se aprende apenas através dos livros e professores, cercados por um ambiente escolar, nas salas de aula.

Atualmente, é possível aprender qualquer coisa através de uma gama variada de informações disponíveis na Internet, não há mais fronteiras. O envolvimento das pessoas, a interação cada vez mais acessível na Sociedade Midiática, ampliam as possibilidades de troca de conhecimentos e de aprendizado mútuo. Para Moran (2008), é importante observar como a Internet pode contribuir com a formação humana:

\footnotetext{
$\mathrm{Na}$ Internet, também desenvolvemos formas novas de comunicação, principalmente escrita. Escrevemos de forma mais aberta, hipertextual, conectada, multilinguística, aproximando texto e imagem. Agora começamos a incorporar sons e imagens em movimento. A possibilidade de divulgar páginas grupais na Internet gera uma grande motivação, sensibilidade, responsabilidade para professores e alunos. Todos se esforçam por escrever bem, por comunicar melhor as suas ideias, para serem bem aceitos, para 'não fazer feio' [...] (MORAN, 2008, p. 06).
}

Ou seja, o conhecimento nesta Sociedade Midiática é atualizado a cada instante, revisado, modificado e ampliado. Assim, há pouco lugar para o estático, pronto e acabado. O que reforça a questão da incompletude do ser humano, ou do ser inacabado, de que tanto Freire (1996) explanava.

Nesta perspectiva, a mídia tem ganhado espaço cada vez maior e criado outras formas de interação, a partir de diversos meios de comunicação. Compreender as interações que se constituem nos espaços de socialização, é fator preponderante para maximizar cada vez mais a qualidade da comunicação nesta diversidade de informações.

É interessante compreender quais são os impactos sociais que a comunicação tem gerado na vida das pessoas e comunidades e qual relação à mesma tem com a qualidade de vida dos cidadãos que, muitas vezes, passam despercebidos. Como visto, não basta apenas reter e transmitir informações, é essencial interpretar e selecionar, relacionar e analisar.

Neste contexto, será que as mudanças econômicas e financeiras de uma Sociedade Midiática influenciam diretamente na relação do homem com a mídia? Será que o homem percebe esta 
influência? Como? É possível perceber frente a tantas informações com um tempo quase ínfimo para esta questão?

Será que o homem compreende o quanto aprende na relação homem-tecnologia? Se ele compreende, o que tem ganhado - ou perdido? Como será a relação do homem atual com os espaços virtuais? Seria possível hoje o homem se perceber sem o uso destas ferramentas midiáticas para uma interação/comunicação?

Questionamentos como estes são instigantes. E são reflexões que devem permear outras tantas discussões e análises. Uma vez que a relação da mídia com o sujeito vai acontecendo assim, sem muita investigação do como, do porque e de que forma. Ela acontece!

Enfim, compreende-se que a sociedade atual vivencia o uso das ferramentas e aparatos tecnológicos sem ter muito claro sua importância em relação ao diálogo nas relações, afinal, tudo parece tão automatizado, tão pronto e definido que parece que sempre foi assim.

Então, para que serve a educação escolar de hoje? Qual deve ser o seu lugar no século XXI? Está claro que a educação escolar de hoje deve ser reflexiva e crítica, trabalhar com os alunos a compreensão da sociedade e de todo o universo de informação que não se dá somente no ambiente escolar. Para Dowbor (2001):

O grande desafio da educação é o de mobilizar as suas forças para reconstruir uma convergência entre o potencial tecnológico e os interesses humanos [...] O novo peso do conhecimento no planeta, e da educação nos processos de reprodução social, podem constituir uma poderosa alavanca de humanização social (DOWBOR, 2001, p. 45).

Neste novo cenário, a escola se caracteriza como um dos poucos locais onde ainda é possível a reunião presencial para reflexão e discussão do mundo, lugar de produção de conhecimento. E é preciso se atentar para os mais variados aparatos tecnológicos, cada vez mais disponíveis e acessíveis, e se aproximar das Tecnologias da Informação e Comunicação (TIC) com vistas a se apropriar da nova linguagem do presente século.

\section{A questão do diálogo entre os saberes Comunicação e Educação}

A Educação Escolar no contexto midiático tem um grande desafio. Há uma nova geração, a dos chamados 'nativos digitais' (PRENSKY, 2001). É preciso que a escola esteja preparada para atuar neste contexto. São novos elementos que alteram dinâmicas sociais, culturais e econômicas. O que gera diálogo diferenciado entre professor e educando. 
Neste sentido, não se trata mais de transmitir conhecimento. A esse respeito, Masetto (2007) destaca o novo papel do professor. Segundo ele,

[...] o professor assume uma nova atitude. Embora, uma vez ou outra, ainda desempenhe o papel de especialista que possui conhecimentos e/ou experiências a comunicar, na maioria das vezes, desempenhará o papel de orientador das atividades do aluno, de consultor, de facilitador da aprendizagem de alguém que pode colaborar para dinamizar a aprendizagem do aluno, desempenhará o papel de quem trabalha em equipe, junto com o aluno, buscando os mesmos objetivos [...] (MASETTO, 2007 p.142).

A escola e os professores são cada vez mais necessários no processo de formação do educando. Deve-se favorecer ao educando essa aprendizagem de modo colaborativo e contextualizado.

Percebe-se que o professor não é mais o principal responsável para que novas práticas sejam desenvolvidas a partir das tecnologias. As novas formas de se comunicar, de se relacionar, de buscar, de selecionar informações e de fazer com que elas se transformem em conhecimento têm trazido mudanças radicais para a sociedade. Consequentemente, essas mudanças não se refletem apenas na sala de aula, na prática de ensino do professor e na aprendizagem do aluno, mas na escola como um todo (VOSGERAU, 2012, p. 35).

A criatividade pode surgir da troca de experiências e é preciso criar condições para novos espaços criativos; e para os novos aparatos tecnológicos que vão surgindo a cada instante. Deste modo, é preciso uma integração destas tecnologias ao fazer pedagógico. São tantos novos recursos e novas tendências que se fazem necessários estar atento a tudo visando à construção de novos conhecimentos.

É interessante perceber a relação do sujeito com a mídia a partir das facilidades disponíveis (mesmo que não sejam tão fáceis de usar) com o advento das tecnologias - uma vez que a Internet é uma ferramenta que representa um modo diferente de efetivar a comunicação e o processamento social da informação. Segundo Moran (2008):

A Internet é uma tecnologia que facilita a motivação dos alunos, pela novidade e pelas possibilidades inesgotáveis de pesquisa que oferece. Essa motivação aumenta, se o professor a faz em um clima de confiança, de abertura, de cordialidade com os alunos. Mais que a tecnologia, o que facilita o processo de ensino-aprendizagem é a capacidade de comunicação autêntica do professor, de estabelecer relações de confiança com os seus alunos, pelo equilíbrio, competência e simpatia com que atua (MORAN, 2008, p. 06).

Perceber que o diálogo é essencial para favorecer uma educação democrática e cidadã se tornou inevitável e fundamental. Neste contexto social e tecnológico se percebe a necessidade de ampliar os olhares da escola. Ela não está fora da sociedade, pelo contrário, está imersa e torna-se inevitável discutir acerca de seu papel na formação do educando. 
Paulo Freire (1983) defendia que não há ensino e aprendizagem sem diálogo. O diálogo é essencial para favorecer uma comunicação democrática e cidadã. Para Freire, educar é 'impregnarse de sentido'. O que seria diálogo senão comunicação?

É possível inferir que a Educação prescinde, a priori, da Comunicação. Temer (2005) acredita que comunicar "é a ação de tornar comum uma ideia, ou ainda, uma ação que não se realiza sobre a matéria, mas sobre o outro". Para a autora, a "comunicação é mais do que especificamente o ato de comunicar e também algo diferente do objetivo ou do resultado desta comunicação" (TEMER, 2005, p. 276). Ela explica que “a comunicação envolve manipulação de ideias" e pode-se acrescentar ainda a manipulação de saberes, de conhecimentos, informações etc.

Portanto, educar também 'envolve a manipulação de ideias', seja para uma formação crítica, autônoma e democrática do cidadão, seja para uma formação de pessoas cujo objetivo é a manutenção de um sistema que não prioriza a criticidade, a autonomia e a democracia de um povo. É interessante uma aproximação da compreensão de Bakhtin (1999) que explica que:

Educar significa propiciar e desencadear processos de auto-organização nos neurônios e nas linguagens das pessoas. [...] enquanto adquirem novas informações e conhecem novas linguagens, os aprendentes devem poder também [...] deixar soltos os laços de seus significantes. Quem ensina apenas há de mostrar pistas, insinuar ritmos para a dança das linguagens (BAKHTIN, 1999, p. 71).

Entender que educar pode ser simplesmente comunicar aos alunos pistas, caminhos e possibilidades, ou seja, fazer pensar, propiciar e desencadear processos internos facilita-nos a compreensão de que embora Educação e Comunicação sejam áreas distintas é inevitável uma abordagem sobre os principais elementos que as colocam uma zona de interseção e de interesse em alguns momentos, no que tange às relações humanas.

Percebe-se que Educação e Comunicação aparecem num patamar de mesma importância no processo de transformação social e individual, mesmo que em graus distintos e/ou proporções diferentes (do ponto de vista de quem interpreta). O fato é que estas duas áreas se complementam, interagem, dialogam e estão intrinsecamente ligadas. Há uma interdependência inerente neste processo, o que transcende a ideia de áreas isoladas ou simplesmente independentes.

E ao longo do tempo, o desenvolvimento das mídias e suas transformações sociais tem levado às escolas um desafio constante, qual seja: preparar o educando, enquanto cidadão, para a leitura de mundo, como discutido por Freire (1991) em seu livro 'A importância do ato de ler'. Nesta direção, a escola deixa de ser um 'locus' único para a formação humana e a Comunicação não é apenas um instrumento para as relações humanas. E Barbero (1999) faz um alerta: 
A escola está perdendo importância na medida em que é incapaz de interagir com o horizonte cultural dos jovens. [...] a escola vai continuar a ser necessária na medida em que for ao encontro desses novos modos de ler, de escrever. O professor vai perder sua função repetitiva, sua função de, como direi, vigilante, polícia, para adquirir um status, um ofício muito mais alto (BARBERO, 1999, p.78).

Ao longo dos anos, a Educação Escolar tem compreendido que o diálogo entre as várias áreas do conhecimento é fundamental para contribuir com a aprendizagem humana. Portanto, sabese que já não se apreende apenas na Escola. Assim, Toschi (2011) alerta que a Escola neste processo deve ficar atenta:

O grande volume de informação a que se está exposto atualmente dificulta a comunicação, em especial na sua dimensão social e cultural. Isso é um complicador para a escola que, de mais importante espaço de divulgação do conhecimento, passa a ser apenas mais um espaço, embora importante, de divulgação e circulação de saberes, dentre tantos outros, em especial a Internet (TOSCHI, 2011, p.4).

Portanto, conforme visto, apreende-se a partir da multiplicidade de ideias (tudo ao mesmo tempo, lado a lado), daí a necessidade de entender que a interdisciplinaridade é cada vez mais constante no cotidiano, na maioria das vezes, imprescindível. Barthes (2004, p. 99) explica que “para fazer interdisciplinaridade não basta tomar um 'assunto' (um tema) e convocar em torno duas ou três ciências. A interdisciplinaridade consiste em criar um novo que não pertença a ninguém".

Neste contexto, torna-se fundamental uma maior aproximação entre as várias áreas do saber: como a Linguística, a Sociologia, a Antropologia, as Ciências Sociais etc. Deste modo, a Educação não ficará à parte da sociedade preparando um educando alheio ao mundo em que vive.

Não se trata, portanto, de apenas juntar as Ciências ou Teorias, mas de produzir novos conhecimentos com base nelas. Compreendendo isso, a Educação tem a oportunidade de seguir por caminhos que possibilitem ao indivíduo uma formação plena, que o prepare para viver (hoje) na Era da Sociedade Midiática, no mundo das tecnologias.

Então, como a Escola pode preparar o sujeito na sociedade atual sem considerar a importância de se atentar para o que está posto? Torna-se cada vez mais claro que a Sociedade Midiática, com sua vasta gama tecnológica, informacional e comunicacional, faça parte de constantes discussões, reflexões e ações no campo educacional.

Linhares (2007) considera que "os processos de aprendizagem e de apropriação do conhecimento passam a serem repensados e entendidos também como processos de comunicação, construção de regras e intercâmbios sociais". Isso porque o processo de transformação "das ciências 
de base, aliada ao desenvolvimento tecnológico, tem proporcionado um grande exercício de revisão e reconstrução epistemológica" (LINHARES, 2007, p. 21).

Neste sentido, pode-se confirmar que a apropriação do conhecimento se dá, também, em outros espaços, e não apenas na Escola, no ambiente educacional. A Comunicação, os atos comunicativos e os instrumentos desenvolvidos para se comunicar, reforçam a possibilidade de aprender em espaços não formais de ensino.

E, ainda, muito mais que isso, reforça que a própria Educação Escolar também pode e deve buscar a contribuição da Comunicação para uma aprendizagem mais crítica, reflexiva e cidadã, saindo de um lugar meramente 'conteudista', conforme apontam Freire \& Guimarães (1987, p. 84), “ela se obriga a deixar de ser um espaço preponderantemente fabricador de memórias repetitivas, para ser um espaço comunicante e, portanto, criador".

Quando a escola despeja conteúdos sem significados, sem a compreensão e reflexão dos alunos acerca dos mesmos, ela se torna apenas um locus conteudista (o conhecimento não é produzido, difundido e apreendido) e não um espaço de diálogo/comunicação, de reflexão, de ensino e de aprendizagem. Sartori \& Roesler (2007) destacam o papel da mídia na sociedade atual, e, consequentemente, as exigências para os educadores neste contexto:

O papel preponderante que a mídia tem ocupado no desenvolvimento econômico e cultural e sua presença cada vez mais intensa na agenda do entretenimento e nos processos de criação, lazer, trabalho e formação, exige dos educadores que concebam novos procedimentos metodológicos e apresentem posturas que comtemplem processos diferenciados de aprendizagem, respeitando as sensibilidades e subjetividades advindas de um convívio maior com as tecnologias de informação e da comunicação e suas linguagens (SARTORI \& ROESLER, 2007, p. 99).

Setton (2010) afirma que o aprendizado neste contexto é contínuo, portanto, a competência do professor também ganha novos desafios, conforme destaca a seguir:

\begin{abstract}
A competência do professor deve se deslocar no sentido de incentivar a aprendizagem e o pensamento. $\mathrm{O}$ professor se torna um animador da inteligência coletiva dos grupos que estão em seu encargo. Sua atividade será centrada no acompanhamento e na gestão das aprendizagens; do incitamento à troca de saberes, à mediação relacional e simbólica, a pilotagem personalizada dos percursos de aprendizagem. A proposta é aprendizado contínuo (SETTON, 2010, p. 103).
\end{abstract}

Encontram-se, também, descrito nos PCN (1998) apontamentos para que a Escola esteja atenta às demandas atuais e não negligencie o conhecimento:

As demandas atuais exigem que a escola ofereça aos alunos sólida formação cultural e competência técnica, favorecendo o desenvolvimento de conhecimentos, habilidades e atitudes que permitam a adaptação e a permanência no mercado de trabalho, como também a formação de cidadãos críticos e reflexivos, que possam exercer sua cidadania ajudando na 
construção de uma sociedade mais justa, fazendo surgir uma nova consciência individual e coletiva, que tenha a cooperação, a solidariedade, a tolerância e a igualdade como pilares (PCN, 1998, p. 138).

Portanto, neste contexto social e tecnológico se percebe a necessidade de ampliar os olhares da Educação Escolar. É notório que ela não está fora da sociedade, pelo contrário, está imersa. Mas, é preciso ter cuidado, de acordo com Masetto (2007, p. 144), pois "é importante não nos esquecermos de que a tecnologia possui um valor relativo: ela somente terá importância se for adequada para facilitar o alcance dos objetivos e se for eficiente para tanto".

De acordo com Freire (1996, p. 98), “outro saber que não posso duvidar um momento sequer na minha prática educativo-crítica é o de que, como experiência especificamente humana, a educação é uma forma de intervenção no mundo".

Encontram-se ainda nos escritos de Freire (1983) a afirmação de que:

\begin{abstract}
Educar e educar-se, na prática da liberdade, é tarefa daqueles que sabem que pouco sabem por isto sabem que sabem algo e podem assim chegar a saber mais - em diálogo com aqueles que, quase sempre, pensam que nada sabem, para que estes, transformando seu pensar que nada sabem em saber que pouco sabem, possam igualmente saber mais (FREIRE, 1983, p.25).
\end{abstract}

E assim, Freire (1996) acreditava indiscutivelmente que para que a aprendizagem humana fosse completa seria necessária a formação crítica do cidadão. Ainda é pertinente para os dias atuais entender que não há aprendizagem sem o diálogo, sem comunicação.

\title{
4 Considerações finais
}

Não se pode negar a possiblidade de a Educação, inclusive no contexto escolar, de contribuir para uma mudança de concepção de uma sociedade. Principalmente, aliada às possibilidades da Comunicação em oportunizar ao homem interações diversas na sociedade contemporânea, o que as tornam indispensáveis, juntas, na formação do indivíduo e em sua transformação social.

Resta saber se todas essas possibilidades de formação plena do indivíduo, para a compreensão e exercício da cidadania, dos direitos humanos, tanto no campo comunicacional, quanto no educacional, são favorecidas no dia-a-dia da escola, na vida dos educandos. Assim sendo, é perceptível que ambas, Educação e Comunicação, na Sociedade Midiática, dialogam e sua relação é intrínseca. Elas têm potenciais para contribuir com a formação do cidadão no contexto atual.

O diálogo é ponto sine qua non para entender como é possível que a Comunicação e Educação possam favorecer a compreensão de que são elementos fundamentais e constituidores da 
cidadania. É sabido que a relação entre o homem e a tecnologia tem gerado mudanças no modo de vida das pessoas. As tecnologias têm possibilitado, a partir da interação social propiciada pela mídia, transformações culturais, sociais e econômicas.

A mídia tem o poder de contribuir com a construção de um novo tipo de sociedade. Cada vez mais a mídia se configura num espaço que vai além da interação, ela pode favorecer o diálogo e a socialização, dentre outras possibilidades. E juntas, as áreas da Educação e da Comunicação podem favorecer mudanças no cenário da formação humana.

Não é possível impingir à Comunicação e à Educação a responsabilidade de mudar o mundo, mas, elas são, sem dúvida, Ciências mais próximas da formação do indivíduo para vivenciar a contemporaneidade. Juntas elas podem oportunizar ao ser humano novos espaços de interação e de aprendizados.

Por isso mesmo, torna-se fundamental compreender que Comunicação e Educação podem ser instrumentos de poder e suas potencialidades são capazes de engendrar a vida humana em novos caminhos e soluções para os percalços vivenciados na contemporaneidade.

O assunto não se esgota. Ainda há muito que compreender, refletir, discutir acerca das contribuições e potencialidades desta Sociedade Midiática, assim como da Comunicação e da Educação, com a construção da cidadania, de um mundo justo e igualitário.

Artigo submetido em 20/09/2013 e aceito em 01/10/2013.

\section{Referências}

BAKHTIN, Mikhail. Marxismo e filosofia da linguagem. São Paulo: Hucitec, 1999.

BARBERO, Jesus Martín. Sujeito, comunicação e cultura. Revista Comunicação \& Educação, São Paulo, n. 15, 1999. Entrevista concedia a Fígaro e Bacega. Disponível em:

<http://www.revistas.univerciencia.org/index.php/comeduc/article/view/4089/3841>. Acesso em: 15 maio 2013.

BARTHES, Roland. O Rumor da língua. São Paulo: Martins Fontes, 2004.

BRASIL. Parâmetros curriculares nacionais: terceiro e quarto ciclos do ensino fundamental. Introdução aos parâmetros curriculares nacionais / Secretaria de Educação Fundamental. Brasília, DF: MEC/SEF, 1998.

DOWBOR, Ladislau. Tecnologias do conhecimento: os desafios da educação. Petrópolis, RJ: Vozes, 2001.

FREIRE, Paulo. A importância do ato de ler. São Paulo: Cortez/Autores Associados, 1991. 
FREIRE, Paulo. Extensão ou comunicação? 10. ed. Rio de Janeiro: Paz e Terra, 1983.

FREIRE, Paulo. Pedagogia da autonomia: saberes necessários à prática educativa. São Paulo: Paz e Terra, 1996.

FREIRE, Paulo; GUIMARÃES, Sérgio. Aprendendo com a própria história. Rio de Janeiro: Paz e Terra, 1987.

GOBBI, Maria Cristina. O legado da ALAIC para a difusão da Escola Latino Americana de Comunicação. Revista ALAIC, [S.1.], n. 8-9, v. 5, 2011.

LEVY, Pierre. Cibercultura. São Paulo: Ed. 34, 1999.

LINHARES, Ronaldo Nunes. Gestão em comunicação e educação: o audiovisual no espaço escolar. Maceió: UFAL, 2007.

MACLUHAN, M. Os meios de comunicação como extensão do homem. 9. ed. São Paulo: Cultrix, 1998.

MASETTO, Marcos Tarciso. Mediação pedagógica e o uso da tecnologia. In: MORAN, José Manuel; MASETTO, Marcos T.; BEHRENS, Marilda Aparecida. Novas tecnologias e mediações pedagógicas. 13. ed. São Paulo: Papirus, 2007.

MELO, José Marques de. Teoria da comunicação: paradigmas latino-americanos. Petrópolis: Vozes. 1998.

MORAN, José Manuel. Ciência da Informação: como utilizar a internet na educação, 2008. Disponível em: 〈http://www.scielo.br/prof_moran>. Acesso em: 20 abr. 2013.

NERY, Vanda Cunha; TEMER, Ana Carolina R. P. Para entender as teorias da comunicação. Uberlândia: Aspecctus, 2009.

PRENSKY, Marc. Nativos digitais, imigrantes digitais. De On the Horizon NCB University Press, v. 9, n. 5, out. 2001.

SARTORI, Ademilde S.; ROESLER, Jucimara. Mídia e educação: linguagens, cultura e prática pedagógica. In: TORRES, Patrícia Lupion (Org.). Algumas vias para entretecer o pensar e o agir. Curitiba: SENAI-PR, 2007.

SETTON, Maria das Graças. Mídia e educação, São Paulo. Contexto, 2010.

TEMER, Ana Carolina. As bases sociológicas nos estudos das teorias da comunicação. Comunicação Veredas. ano 4, n. 4, São Paulo: Unimar, 2005.

THOMPSON, John. Mídia e modernidade: uma teoria social da mídia. Petrópolis: Vozes, 1998. 
TOSCHI, Mirza Seabra. CMDI - Comunicação mediada por dispositivo indutor: elemento novo nos processos educativos. In: LIBÂNEO, José Carlos; SUANNO, Marilza Vanessa Rosa (Orgs.). Didática e escola em uma sociedade complexa. Goiânia: CEPED, Editora da PUC-Goiás, 2011.

TREMBLAY, Gaëtan. As TIC e o sistema educacional. Os temores de Innis e as esperanças de McLuhan. In: BARBOSA, Marialva Carlos. MORAES, Oswaldo J. (Org.). Quem tem medo da pesquisa empírica. 60 anos UNICAP/ São Paulo: INTERCOM, 2011.

VOSGERAU, Dilmeire Sant'Anna Ramos. A tecnologia nas escolas: o papel do gestor neste processo. In: COMITÊ GESTOR DA INTERNET NO BRASIL - CGI.br. Pesquisa sobre o uso das tecnologias da informação e da comunicação no Brasil: TIC 2011. São Paulo: Comitê Gestor da Internet no Brasil, 2012. Disponível em: <http://op.ceptro.br/cgi-bin/cetic/tic-educacao2011.pdf>. 